\title{
Raman spectroscopic analysis of precious coral Mg-calcite geochemistry: Kinetic effects and natural gradients
}

\author{
K.A. CONNER ${ }^{1 *}$, S.E. KAHNG ${ }^{2}$, M.J. EGAN ${ }^{1}$, S.K. \\ SHARMA $^{1}$ \\ ${ }^{1}$ School of Ocean and Earth Science \& Technology, \\ University of Hawai'i at Manoa (*corresponding author: \\ kconner7@hawaii.edu) \\ ${ }^{2}$ Department of Natural Sciences, Hawai'i Pacific University
}

Marine calcifiers spanning corals, shellfish, algae, and other invertebrates have been subject to increasing research focus due to their rising vulnerability to ocean acidification, a global stressor that has been observed over several decades [1]. Moreover, certain calcifiers such as corals can store geochemical information within their skeletons and thus serve as valuable proxies for studying current and historical changes in the environment [2]. Despite numerous geochemical and mineralogical studies conducted on shallowwater coral species, there has been relatively less work done on deep-water calcitic corals as well as a short supply of geochemical studies that have analyzed an environmentally coherent set of calcitic samples. In order to assess potential spatiotemporal patterns in deep-water calcitic coral geochemistry, we analyze the $\mathrm{Mg}$ content of a considerable calcitic octocoral sample set $(\mathrm{N}=33)$ along a natural depth gradient ( $\mathrm{pH}: 7.3-8.1, \mathrm{~T}: 5-19^{\circ} \mathrm{C}$ ). These Hemicorallium precious corals were collected off the Kona Coast of Hawai' $i$ (200-800 m depth) via the HURL Pisces IV submersible [3] during multiple HURL cruises (2011, 2016, and 2017). Accompanying these samples are relevant oceanographic data from CTD hydrocasts, bottle samples, and HOBO loggers which resolve environmental gradients with increasing depth (temperature, $\mathrm{pH}, \mathrm{DO}, \mathrm{DIC}, \mathrm{TA}$ ). Raman Spectroscopy is a fast, efficient, and non-destructive method that has been employed in previous studies of biogenic Mg-calcites [4-6] and will be used here to analyze the $\mathrm{Mg}$ content within the Hemicorallium samples. Mg content will also be analyzed with respect to slow and fast skeletal growth axes in order to examine the kinetic effects of $\mathrm{Mg}$ incorporation, which could have both geochemical and ecological implications.

[1] Dore et al. (2009) PNAS 106, 12235-12240. [2] Druffel (1997) PNAS 94, 8354-8361. [3] Grigg (2002) Mar. Fish. Rev. 64, 13-20. [4] Bischoff et al. (1985) Amer. Mineral., 70, 581-589. [5] Urmos et al. (1991 ) Amer. Mineral., 76, 641646 (1991). [6] Borromeo et al. (2017) J. Raman. Spectrosc. 48, 983-992. 